\title{
ABSOLUTE CONFIGURATION OF MULINOLIC ACID
}

\author{
IVÁN BRITO* JORGE BORQUEZ ${ }^{\prime}$, EMILY HUAROTE ${ }^{1}$, LUIS LOYOLA', \\ ALEJANDRO CÁRDENAS', MARIO SIMIRGIOTIS
}

\author{
${ }^{1}$ Departamento de Química, Facultad de Ciencias Básicas, Universidad de Antofagasta, Casilla 170, Antofagasta, 1240000, Chile \\ ${ }^{2}$ Departamento de Física, Facultad de Ciencias Básicas, Universidad de Antofagasta, Casilla 170, Antofagasta, 1240000, Chile, \\ ${ }^{3}$ Instituto de Farmacia, Facultad de Ciencias, Universidad Austral de Chile, casilla 567, Valdivia 5090000, Chile.
}

\begin{abstract}
The structure of this mulinolic acid consists of a mulinane skeleton and the corresponding isopropyl, methyl, carboxyl and methyl groups at C3, C8, C5, $\mathrm{C} 13$, respectively, which are $\beta$-oriented, whereas the hydroxyl group at $\mathrm{C} 13$ is $\alpha$-oriented. The cyclopentane (A), ciclohexane (B) and cicloheptene (C) rings are trans $(\mathrm{A} / \mathrm{B})$ and $(\mathrm{B} / \mathrm{C})$ cis fused, and in an envelope, chair, and twist conformation respectively.

In the crystal the molecules are linked by two intermolecular $\mathrm{O}-\mathrm{H} \cdots \mathrm{O}$ hydrogen bond forming bidimensional supramolecular structures with graph-set notation $\mathrm{R}_{4}{ }_{4}(12), \mathrm{R}_{4}{ }_{4}(40), \mathrm{R}_{6}{ }_{6}(46)$ and $\mathrm{C}_{4}(46)$. The absolute configuration of the title compound has been determined from the refinement of the Flack parameter ${ }^{16}$. On this basis the absolute configuration was assigned as $\mathrm{C} 3 R, \mathrm{C} 5 S, \mathrm{C} 8 S, \mathrm{C} 9 S, \mathrm{C} 10 S$ and $\mathrm{C} 13 R$.
\end{abstract}

Keywords: absolute configuration, diterpenoid, X-ray diffraction, crystal and supramolecular structure.

\section{INTRODUCTION}

Mulinum crassifolium is small cushion shrub growing up to $15 \mathrm{~cm}$ commonly known as "chuquicán", "susurco" o "espinilla" which grows in the north of Chile at altitudes above $3500 \mathrm{~m}$. Bitter tasting infusions of the whole plant are used widely in folk medicine, principally in the treatment of diabetes, and bronchial and intestinal disorders ${ }^{1}$. This plant is well recognized as an important source of diterpenes bearing the mulinane skeleton with interesting biological activities ${ }^{2}$. The relative stereochemistry of the title compound was assigned by spectroscopic data and by chemical transformations ${ }^{3}$. In this paper we report the absolute configuration of the title compound which has been determined from the refinement of the Flack parameter ${ }^{15}, \mathrm{x}=0.05(11)$, which indicate that the correct configuration had been assigned against 925, CuK $\alpha$ Bijvoet pairs. On this basis the absolute configuration was assigned as $\mathrm{C} 3 R$, C5S, C8S, C9S, C10S and C13R.

\section{EXPERIMENTAL}

The title compound $\mathrm{C}_{20} \mathrm{H}_{32} \mathrm{O}_{3}$ was isolated using medium pressure column chromatography (MPCC). In a continuation of our program for the chemical study of the Atacama Desert Flora ${ }^{2-6}$, dried aerial parts of Mulinum crassifolium (750 g) collected in April 2014 in the pre-Andean mountain range of Atacama Desert, precordillera de la II Region, Northern Chile were extracted with n-hexane (1 liter, 3 times in the dark, $24 \mathrm{~h}$ each time) and $22 \mathrm{~g}$ of a yellow gum were obtained after evaporation of the solvent. A portion of the extract (10.0 g) was filtered and submitted to a medium pressure column chromatography system composed of an $2.5 \mathrm{~cm} \mathrm{x} 48 \mathrm{~cm}$ medium pressure column (Aceglass inc, Vineland, NY, USA) packed with silicagel (Kieselgel 60 H, Merck, Darmstadt, Germany) using an isocratic solvent system of n-hexane-ethyl acetate (9.0:1.0 $\mathrm{v}: \mathrm{v}$ ) pumped with a medium pressure pump (FMI lab pump, Syosset, NY, USA) with a flow rate of $10 \mathrm{~mL}$-minute. The collected fractions (80) were combined according to TLC analysis (Kieselgel F254 plates, developed with Hexane: EtOAc 8:2 v/v, and spots visualized by spraying with vanillin: sulfuric acid $2 \%$ in ethanol and heating) and fifteen combined fractions were obtained. Fraction $5(350 \mathrm{mg})$ was re-chromatographed using the same chromatographic system and the known compounds: mulin-11,13-dien-20-oic acid ${ }^{6}(120 \mathrm{mg})$ and mulinolic $\operatorname{acid}^{7}(60 \mathrm{mg})$. Recrystallization de mulinolic acid from ethyl acetate a room temperature yielded white crystals, which were suitable for $\mathrm{X}$-ray diffraction analysis. The spectroscopic data showed resemblance with those similar mulinane structures reported in the literature ${ }^{4-11}$. The relative stereochemistry of mulinolic acid was assigned based on careful analysis of the ROESY experiment ${ }^{6}$, and in this work we have assigned the absolute configuration of this diterpene using X-ray crystal analysis.

Mulinolic acid: white crystals, m.p. $178-180{ }^{\circ} \mathrm{C}$. The molecular weigh was determined by orbitrap HR-ESI-MS/MS with a mass spectrometer. [M$\mathrm{H}]:$ required: 319.22752 , found: 319.22766 for $\mathrm{C}_{20} \mathrm{H}_{31} \mathrm{O}_{3}^{-}$(Fig. 1). ${ }^{1} \mathrm{H}$ NMR (Bruker Avance $\left.300 \mathrm{MHz}, \mathrm{CDCl}_{3}\right) \delta \mathrm{ppm}: 0.86(3 \mathrm{H}, \mathrm{d}, \mathrm{J}=5.8 \mathrm{~Hz}, \mathrm{Me}-18$ ), 0.94 (3H, s, Me-17), 1.04 (3H, d, J = 5.8 Hz, Me-19), 1.10 (1H, dd, J = 4.6,
$15.0 \mathrm{~Hz}, \mathrm{H}-15 \beta), 1.32$ (3H, s, Me-16), 1.38 (1H, m, H7 $\beta$ ), 1.47 (4H, m, H-6 $\alpha$, H-4 $\alpha, \mathrm{H}-7 \alpha, \mathrm{H}-2 \beta), 1.51$ (1H, m, H-3 $\alpha), 1.55(1 \mathrm{H}, \mathrm{m}, \mathrm{H}-1 \alpha), 1.63(1 \mathrm{H}, \mathrm{dd}, \mathrm{J}$ $=9.3 / 12.5 \mathrm{~Hz}, \mathrm{H}-14 \beta), 1.84(1 \mathrm{H}, \mathrm{dd}, \mathrm{J}=4.6 / 12.5 \mathrm{~Hz}, \mathrm{H}-14 \alpha), 1.91(1 \mathrm{H}, \mathrm{m}$, $\mathrm{H}-2 \alpha), 1.93(1 \mathrm{H}, \mathrm{m}, \mathrm{H}-1 \beta), 2.08(1 \mathrm{H}, \mathrm{m}, \mathrm{dd}, \mathrm{J}=6.0 / 10.8, \mathrm{H}-9 \beta), 2.16(1 \mathrm{H}, \mathrm{br}$ $\mathrm{d}=10.8 \mathrm{~Hz}, \mathrm{H}-10 \alpha), 2.42(1 \mathrm{H}, \mathrm{dd}, \mathrm{J}=3.0 / 9.4 \mathrm{~Hz}, \mathrm{H}-6 \beta), 2.61(1 \mathrm{H}, \mathrm{dt}, \mathrm{J}=15.0$ $\mathrm{Hz}, \mathrm{H}-15 \alpha), 5.58(1 \mathrm{H}, \mathrm{d}, \mathrm{J}=12.8 \mathrm{~Hz}, \mathrm{H}-11), 5.58(1 \mathrm{H}, \mathrm{d}, \mathrm{J}=12.9 \mathrm{~Hz}, \mathrm{H}-12)$. ${ }^{13} \mathrm{C}$ NMR $\left({ }^{13} \mathrm{C}\right.$ NMR Bruker Avance $\left.75 \mathrm{MHz}, \mathrm{CDCl}_{3}\right) \delta \mathrm{ppm}: 180.2(\mathrm{COOH})$ 133.8 (C-11), 136.5 (C-12), 71.4 (C-13), 58.4 (C-5), 57.7 (C-3), 51.6 (C-10), 48.7 (C-9), 42.2 (C-7), 36.2 (C-14), 35.9 (C-8), 32.4 (C-6), 32.0 (C-4), 30.5 (C-15), 28.9 (C-2), 33.7 (Me-16), 27.5 (Me-17), 25.2 (C-1), 22.6 (Me-19), 22.9 (Me-18). These data, together with HR-MS data and correlations observed in the HSQC and HMBC spectra, are consistent with the structure of mulinolic acid(Figure 1).

Data collection, structural determination and refinement was performed with a Bruker AXS D8-Venture, Triumph- $\mu \mathrm{I}-\mathrm{Cu}$ with graphite-monochromated $\mathrm{CuK} \alpha$ radiation $(1.54178 \AA)$. The structure was solved by direct method, and was refined against $\mathrm{F}^{2}$ by full-matrix least-squares methods using SHELXL ${ }^{12}$. All of the non-hydrogen atoms were refined anisotropically. The hydrogen atoms was located from a difference Fourier map and allowed to ride on their parent $\mathrm{C}$ and $\mathrm{O}$ atoms, with isotropic displacement parameters related to the refined values of the corresponding parent atoms. The final Fourier maps, the electron-density residuals were not significant. Crystallographic data, details of data collection and structure refinement parameters for the title compound is summarized in Table 1. Program used to solve structure: SHELXS-201312, program used to refine structure: SHELXL-201312, molecular graphics ${ }^{13}$. The absolute configuration of the title compound which has been determined from the refinement of the Flack parameter ${ }^{15}, \mathrm{x}=0.05(11)$, indicated that correct configuration had been assigned, against 925 , CuK $\alpha$ Bijvoet pairs.

\section{RESULTS AND DISCUSSION}

The molecular structure and the absolute configuration of the title compound was confirmed by x-ray diffraction analysis of suitable single crystals (Fig. 2). Colorless block crystals of title compound with approximate dimensions $0.200 \times 0.150 \times 0.150 \mathrm{~mm}$ was obtained by slow evaporation of a ethyl acetate solution. The molecular structure consists of a mulinolic acid skeleton with the required isopropyl, methyl, carboxyl and methyl group at $\mathrm{C} 3, \mathrm{C} 8, \mathrm{C} 5, \mathrm{C} 13$ respectively, which are $\beta$-oriented, as in mulinolic acid, whereas the hydroxyl group at C13 is $\alpha$-oriented, (Fig.1). The Cremer and Pople parameters ${ }^{15}$ for the cyclopentane (A), ciclohexane (B) and cicloheptene (C) rings are: $\mathrm{Q}_{2}=0.412(6) \AA, \varphi_{2}=115.6(9)^{\circ} ; \mathrm{Q}_{\mathrm{T}}=0.595(6) \AA, \theta=174.3(6)^{\circ}, \varphi$ $=107(6)^{\circ}$ and $\mathrm{Q}_{2}=0.207(6) \AA, \varphi_{2}=104.4(18)^{\circ}, \mathrm{Q}_{3}=0.592(6) \AA, \varphi_{3}=334.9(6)^{\circ}$, so the conformation for $\mathrm{A}, \mathrm{B}$ and $\mathrm{C}$ rings are: envelope, chair, and twist chair respectively. The $\mathrm{A} / \mathrm{B}$ and $\mathrm{B} / \mathrm{C}$ rings are trans and cis fused respectively. The $\mathrm{OH}$ groups are involved in hydrogen bonding interactions with the average $\mathrm{H} \cdots \mathrm{O}$ distance of $1.955 \AA$ and $\mathrm{O}-\mathrm{H} \cdots \mathrm{O}$ angles of $149^{\circ}$ (Table 2 ), so in the crystal the molecules are linked by two intermolecular $\mathrm{O}-\mathrm{H} \cdots \mathrm{O}$ hydrogen 
bond forming bidimensional supramolecular structures with graph-set notation $\mathrm{R}_{4}(12), \mathrm{R}_{4}(40), \mathrm{R}_{6}(46)$ and $\mathrm{C}_{4}(46){ }^{16}$, (Fig. 3 and Fig. 4). All bond distances and angles are normal.

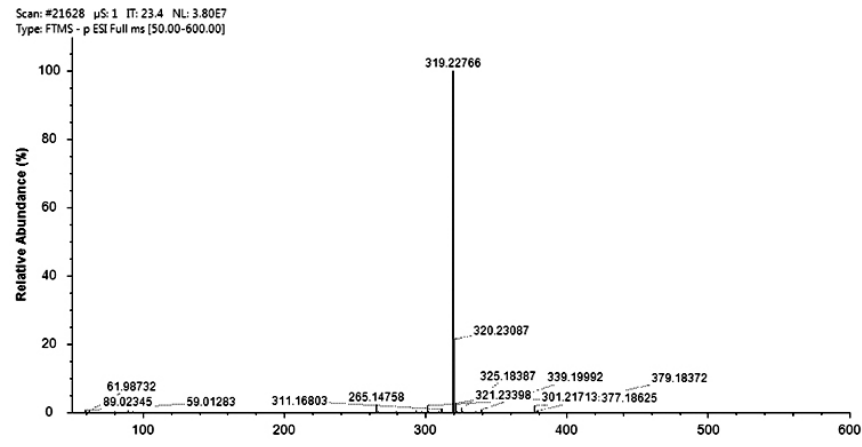

Fig. 1: Full Orbitrap HESI (-) spectra of compound mulinolic acid.

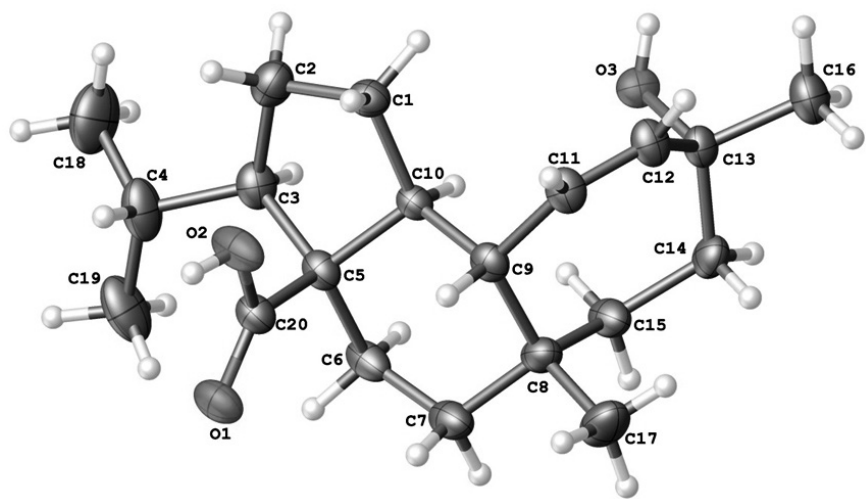

Fig.2: ORTEP Diagram of mulinolic acid. The ellipsoids are shown at the $30 \%$ probability level.

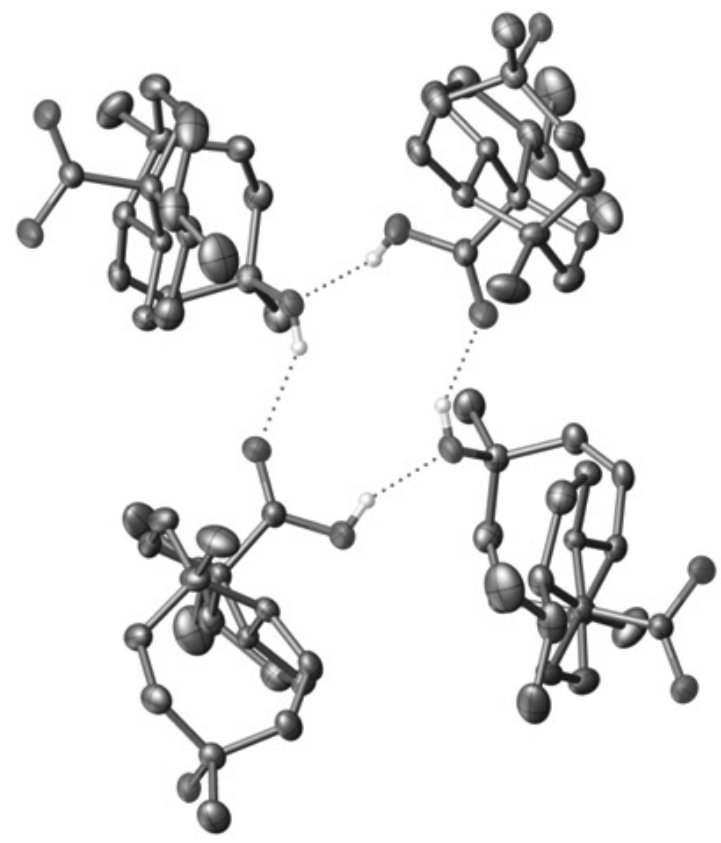

Fig.3 A view of the bi-dimensional supramolecular aggregate, showing the formation of ring with set-graph motif $\mathrm{R}_{4}(12)$ as representative example. For the sake of clarity, $\mathrm{H}$-atoms bonded to $\mathrm{C}$ atoms have been omitted.
Table 1. Crystallographic data, details of data collection and structure refinement parameters for the title compound.

\section{Crystal data}

$\mathrm{C}_{20} \mathrm{H}_{32} \mathrm{O}_{3}$

$\mathrm{Mr}=320.45$

Orthorhombic, $\mathrm{C} 222$

$\mathrm{a}=14.7039(19) \AA \quad \alpha=90^{\circ}$

$\mathrm{b}=22.772(3) \AA \quad \beta=90^{\circ}$

$\mathrm{c}=12.3979(15) \AA \quad \gamma=90^{\circ}$

$$
\mathrm{V}=4151.3(9) \AA^{3}
$$

$\mathrm{Z}=8$

$\operatorname{CuK} \alpha(\lambda=1.54178 \AA)$

$\mu=0.526 \mathrm{~mm}^{-1}$

$\mathrm{T}=296(2) \mathrm{K}$

Colourless, Block, $0.200 \mathrm{x}$

$0.150 \times 0.150 \mathrm{~mm}$

Density (calculated) $/ \mathrm{Mg} / \mathrm{m}^{3} \quad 1.025$

$\mathrm{F}(000)=1408.0$

\section{Data Collection}

Diffractometer Bruker AXS D8-Venture, Triumph- $\mathrm{I} \mu-\mathrm{Cu}$ 2621 reflections with $\mathrm{I}>2 \sigma(\mathrm{I})$

22363 measured reflections

2298 independent reflections

$2 \theta$ range for data collection

$$
\mathrm{R}_{\mathrm{int}}=0.069
$$

Index ranges

7.156 to $111.436^{\circ}$

$-15 \leq \mathrm{h} \leq 15,-23 \leq \mathrm{k} \leq 24,-13$

Refinement

$\mathrm{R}\left[\mathrm{F}^{2}>2 \sigma\left(\mathrm{F}^{2}\right)\right]=0.072$

$\mathrm{wR}\left[\mathrm{F}^{2}\right]=0.201$

215 parameters

$\mathrm{S}=1.14$

$\Delta \rho_{\max }=0.53 \mathrm{e} \cdot \AA^{-3}$

$\Delta \rho_{\max }=-0.23 \mathrm{e} \cdot \AA^{-3}$

Flack parameter ${ }^{15} 0.05(11)$

Goodness-of-fit on $\mathrm{F}^{2} 1.139$

Table 2: Hydrogen-bonding geometry $\left(\AA,^{\circ}\right)$.

\begin{tabular}{|c|c|c|c|c|}
\hline $\mathrm{D}-\mathrm{H} \cdots \mathrm{A}$ & $\mathrm{D}-\mathrm{H}$ & $\mathrm{H} \cdots \mathrm{A}$ & $\mathrm{D} \cdots \mathrm{A}$ & $\mathrm{D}-\mathrm{H} \cdots \mathrm{A}$ \\
\hline $\mathrm{O} 2-\mathrm{H} 2 \cdots \mathrm{O} 3^{\mathrm{i}}$ & 0.82 & 1.83 & $2.600(6)$ & 156 \\
\hline $\mathrm{O} 3-\mathrm{H} 3 \mathrm{~A} \cdots \mathrm{O} 1^{i \mathrm{ii}}$ & 0.82 & 2.08 & $2.776(6)$ & 142 \\
\hline
\end{tabular}

symmetry code: (i) $3 / 2-x, 3 / 2-y, 1 / 2+z$; (ii) $1 / 2+x, 3 / 2-y, 1-z$

\section{CONCLUSIONS}

In order to establish its absolute configuration, a single-crystal X-ray diffraction analysis of mulinolic acid was undertaken. The X-ray molecular model of the title compound (Fig.2), confirmed all the above deductions on its structure and established the absolute configuration as $\mathrm{C} 3 R, \mathrm{C} 5 S, \mathrm{C} 8 \mathrm{~S}, \mathrm{C} 9 \mathrm{~S}$, C10S and C13R

Supplementary material

CCDC- 1548215 contains the supplementary crystallographic data for this article. These data can be obtained free of charge from the Cambridge Crystallographic Data Centre via www.ccdc.cam.ac.uk/data_request/cif.

\section{ACKNOWLEDGEMENTS}

IB acknowledgment Fondequip Program (Grant EQM130021) for the funding to purchase Single Crystal X- ray Diffractometer. JB \& MS thanks FONDECYT (Chile) (Grant 1140178) and fondequip (EQM140002) for financial support. We also thank CONAF (Corporación Nacional Forestal) Chile for the permission and support in the collection of the flora of protected areas of northern Chile.

\section{REFERENCES}

1.- C. Munizaga, H. Gunkel, Notas etnobotánicas del pueblo atacameño de Socaire. Publicación No. 5. Universidad de Chile, 1958.

2.- J.Bórquez, A. Ardiles, L. A. Loyola, L.M.Peña-Rodriguez, G.M. MolinaSalinas, J. Vallejos, I.G.Collado, M.J. Simirgiotis. Molecules, 19, 3898, (2014)

3.- I.Brito, M. J. Simirgiotis, A. Brito, Werner, M. R., Bórquez, J., Winterhalter, P., A. Cárdenas. Journal of the Chilean Chemical Society 60, (1), 2864, (2015)

4.- I.Brito, J. Bórquez, M.Simirgiotis, M. Neves-Vieira, G.Jerz, P.Winterhalter, M. Bolte, A. Cárdenas. Zeitschrift für KristallographieNew Crystal Structures 229, 399, (2014) 
5.- J.,Bórquez, N.L. Bartolucci, C. Echiburú-Chau, P.Winterhalter, J. Vallejos, G. Jerz, M.J. Simirgiotis. Journal of the Science of Food and Agriculture 96, (8), 2832, (2016)

6.- L. A. Loyola, J. Bórquez, G. Morales, A. San Martín. Phytochemistry, 44 649, (1997)

7.- L. A. Loyola, J. Bórquez, G. Morales, A. San Martín. Phytochemistry, 4, (1), 165, (1996)

8.- L.A. Loyola, J.Bórquez, G. Morales, A. San Martín., Phytochemistry, 53, 96, (2000)

9.- L.A. Loyola, J. Bórquez, G.Morales, A. San Martín. Phytochemistry, 45 (7), 1465, (1997)
10.- I. Brito, J. Bórquez, L. A. Loyola, A. Cárdenas, M. López-Rodríguez. Acta cryst, E 64, o1209, (2008)

11.- I. Brito, J. Bórquez, J.Albanez, M. Bolte, L. M. Peña-Rodriguez. Acta Cryst, E 66, 02452, (2010)

12.- G. M. Sheldrick, Acta Cryst. 112 , A64, (2008)

13.- O.V. Dolomanov, L.J. Bourhis, R.J. Gildea, J.A.K. Howard, H. Puschmann, J. Appl. Cryst., 42, 339, (2009)

14.- D.Cremer, J.A. Pople. J.Am.Chem.Soc. 97, 1354, (1975)

15.- H.D. Flack. Acta Cryst. A39, 876, (1983)

16.- J. Bernstein, R.E. Davis, L. Shimoni, N.-L. Chang. Angew. Chem. Int. Ed. Engl. 34, 1555, (1995) 